\title{
Synthesis of Poly(vinyl alcohol) / Silica Gel Polymer Hybrids by In-Situ Hydrolysis Method
}

\author{
Ryo Tamaki and Yoshiki Chujo* \\ Department of Polymer Chemistry, Graduate School of Engineering, Kyoto University, Yoshida, Sakyo-ku, \\ Kyoto 606-8501, Japan
}

\begin{abstract}
Homogeneous poly(vinyl alcohol) (PVA)-silica gel polymer hybrids were prepared by in-situ hydrolysis of poly(vinyl acetate) (PVAc) in a solgel reaction mixture with tetramethoxysilane (TMOS). The degree of hydrolysis was evaluated by FTIR and ${ }^{13} \mathrm{C}$ CP/MAS NMR; it increased with an increase in the acid catalyst and reached $85 \%$ with $1.6 \mathrm{ml}$ of $0.1 \mathrm{M} \mathrm{HCl}$. The homogeneity of the polymer hybrids obtained was maintained when the reaction was performed at $60^{\circ} \mathrm{C}$. However, the polymer hybrid became turbid with an increase of the amount of catalyst present when the reaction was conducted at room temperature. The homogeneity of the polymer hybrids obtained was evaluated by nitrogen sorption porosimetry of a porous silica that was obtained by charring the PVA hybrid. The results confirmed the molecular-level dispersion of the PVA in the hybrid. (C) 1998 John Wiley \& Sons, Ltd.
\end{abstract}

Keywords: poly(vinyl alcohol) (PVA); sol-gel; polymer hybrid

Received 24 September 1997; accepted 23 December 1997

\section{INTRODUCTION}

In recent years, organic-inorganic polymer hybrids with a large variety of functionality have been studied intensively. The combination of the two components at a molecular level would provide novel properties that are hardly obtained from conventional organic or inorganic materials. It results, for instance, in waveguides, ${ }^{1-5}$ optical

* Correspondence to: Yoshiki Chujo, Department of Polymer Chemistry, Graduate School of Engineering, Kyoto University, Yoshida, Sakyo-ku, Kyoto 606-8501, Japan.

Contract/grant sponsor: Ministry of Education, Science, Sports and Culture, Japan

Contract/grant sponsor: Grant-in-Aid for Scientific Research on Priority Areas; Contract/grant number: 08231242. biosensors ${ }^{6}$ or thermally stable nonlinear optical materials. $^{7-10}$ The homogeneous combination of two materials also produces an enhancement of the mechanical strength of organic polymers such as poly(dimethylsiloxane) with silica particles ${ }^{11-15}$ or a modification of the mechanical properties of silica by introduction of organic polymers into the silica phase. ${ }^{16}$ The hybrid materials are also potential candidates for catalysts ${ }^{17-19}$ and gas separation membranes. ${ }^{20-24}$

The sol-gel technique applied to metal alkoxides is one of the most efficient methods for the preparation of composite materials. The method comprises initial hydrolysis of those metal alkoxides and subsequent condensation and removal of the solvents, resulting in metal oxides (Scheme 1 top) ${ }^{25-30}$ The advantage of the sol-gel technique for preparing composite materials is the low reaction temperature, e.g. room temperature, at which the reactions are conducted, while the conventional melt fusion technique of silica glasses needs a high temperature. Thus, it enables the incorporation of organic elements into inorganic materials without deterioration of their functionality. It is also noteworthy that silica gels obtained by the sol-gel reaction contain a large number of residual hydroxyl groups.

We have succeeded in preparing homogeneous organic-inorganic polymer hybrids by incorporating organic polymers such as poly(2-methyl-2oxazoline), poly(vinylpyrrolidone) or $\operatorname{poly}(N, N$ dimethylacrylamide) into the sol-gel reaction mixture of alkoxysilanes. ${ }^{31-41}$ The residual silanol groups in the silica gel and amide groups in the polymers would develop hydrogen-bonding interactions which would help uniform dispersion of each segment. As a precondition for the formation of homogeneous polymer hybrids, polymers should be dispersed uniformly in the sol-gel reaction solution. Organic polymers with highly polar functional groups, however, aggregate as the sol-gel reaction proceeds, to form a silica matrix due to the strong interaction between the polymers themselves.

In our group, a method has been utilized to 


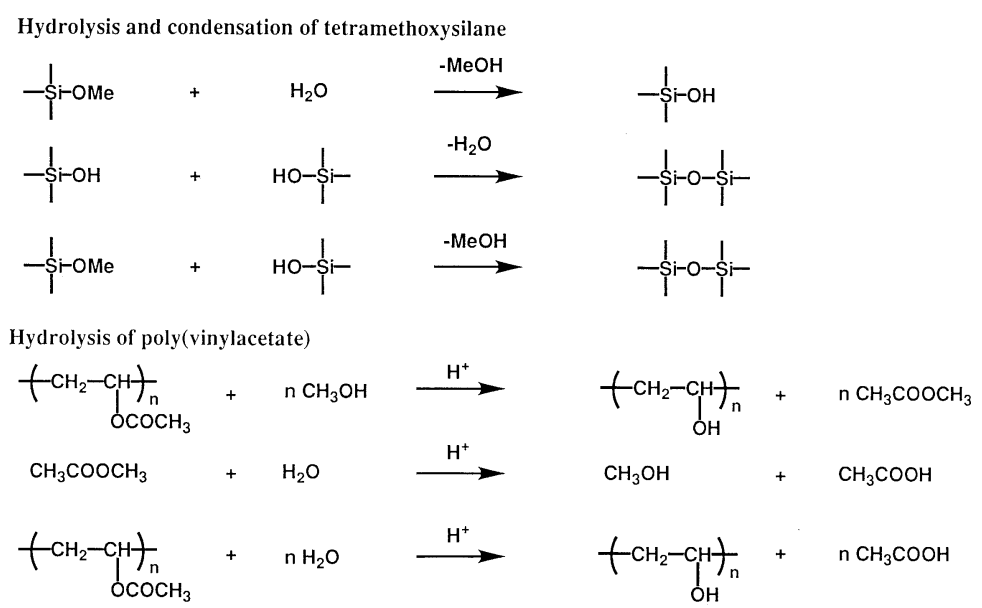

Scheme 1 Top: reductions involved in the conventional sol-gel technique for preparing composite materials. Bottom: PVAc hydrolysis.

suppress the aggregation, namely the modification of these functional groups by adequate substitutes. For example, hydroxyl and amino groups of chitosan were converted into urethane and phthalimide groups, respectively. These functional groups act not only as hydrogen-bonding accepting groups but as the hindering groups for the aggregation by diminishing the polarity.

These methods, however, altered the structure of the organic polymers and affected their properties. In some cases their high polarities play an important role in manifestation of unique properties such as gas-barrier or metal-chelating activities. ${ }^{43}$ Thus, another synthetic technique is desired to incorporate the polymers without such a modification.

Here we introduce a novel synthetic method in which precursor polymers were employed instead of targeted organic polymers. The method comprises the initial incorporation of the precursors of desired polymers into a sol-gel reaction solution of alkoxysilanes and the following simultaneous hydrolysis of the functional groups of the precursor polymers and alkoxysilanes. PVAc was used as a precursor for the synthesis of PVA and silica gel polymer hybrids.

\section{EXPERIMENTAL}

\section{Chemicals}

TMOS (Tokyo Kasei Kogyo Co. Ltd) was used after distillation under nitrogen. Methanol (Wako Pure Chemical Industries Ltd) was used after distillation with sodium under nitrogen. PVAc (Aldrich Chemical Co. Inc., average $M_{\mathrm{w}} \quad c a$ 167 000) and $0.1 \mathrm{M} \mathrm{HCl}$ (Wako Pure Chemical Industries Ltd) were used as supplied.

\section{Preparation of poly(vinyl alcohol) and silica gel hybrids}

PVAc $(0.4 \mathrm{~g}$ or $1.0 \mathrm{~g})$ was dissolved in $20 \mathrm{ml}$ of methanol. TMOS $(2.0 \mathrm{~g})$ and $0.1 \mathrm{M} \mathrm{HCl}$ were added to the solution with continuous mixing at ambient temperature. The reaction mixture was stirred at the same temperature for $5 \mathrm{~h}$ and subsequently heated at $60{ }^{\circ} \mathrm{C}$ for one week (or left at room temperature for two weeks) with an aluminum foil cover having a few pinholes. After the heating period, a hard glass-like material was obtained. These reactions were carried out in air.

\section{Measurement}

The dried gel obtained was crushed into powder and kept in a desiccator until the analyses were conducted. Thermal gravimetric analysis (TGA) was performed on a Shimadzu TG-30, TGC-30 system with a heating rate of $10^{\circ} \mathrm{C} \mathrm{min}{ }^{-1}$ in air. Fourier transform infrared (FTIR) spectra were obtained from $\mathrm{KBr}$ powder-pressed pellets on a Perkin-Elmer 1600 Series FT-IR instrument. Solidstate ${ }^{13} \mathrm{C}$ CP/MAS NMR spectra were measured on a JNM-GSX FT-NMR spectrometer. The data were obtained in the mode of total suppression of 
<smiles>CO[Si](C)(OC)OC</smiles><smiles>C[C@@H]([C@@H](CC(C)(C)C)OC(C)(C)C)C(C)(C)C</smiles>

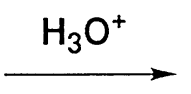<smiles>CCC(O)CC(COC(C)=O)CC(O)CC(O)CC(O)CC(C)C</smiles>
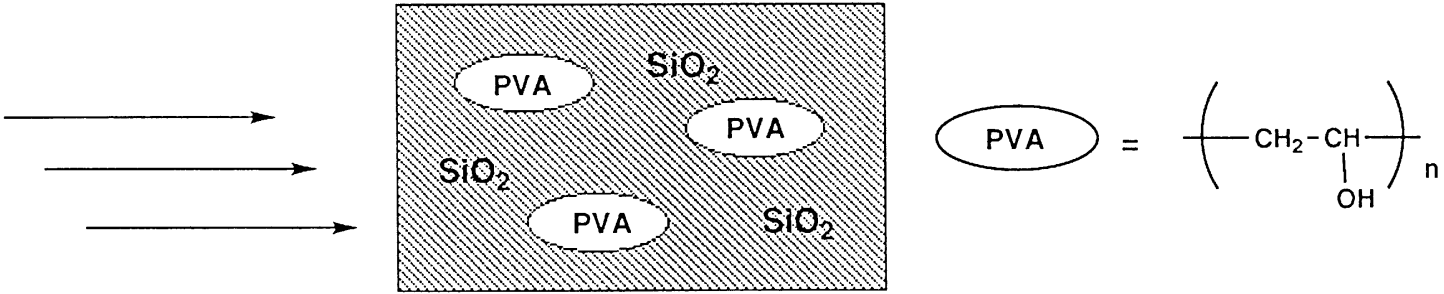

Scheme 2 Preparation of polymer hybrids.

spinning sidebands (TOSS) at a frequency of $100.15 \mathrm{MHz}$ at ambient temperature. Nitrogen absorption porosimetry of a porous silica obtained by charring the polymer hybrid at $600{ }^{\circ} \mathrm{C}$ under the ambient atmosphere was conducted with a BEL Japan Inc. instrument. The porous silica was dried at $200{ }^{\circ} \mathrm{C}$ for $2 \mathrm{~h}$ at reduced pressure under a nitrogen atmosphere before the measurement. A surface area, a pore volume and a pore size were calculated with the MP equation program supplied with the apparatus. ${ }^{44}$

\section{RESULTS AND DISCUSSION}

PVA has high crystallinity due to the hydroxyl groups in its side-chain. The groups cause the phase separation when the polymer is used as a starting material for the synthesis of hybrids with silica gel. PVAc, on the other hand, has acetyl groups as repeating units and its polarity is not as strong as that of PVA. The polymer hybrid containing PVAc was prepared by Landry et al. ${ }^{4-47}$ by utilizing the hydrogen-bonding interaction of acetyl groups in the polymer and the residual silanol groups in silica gels. It was also reported that the functional groups of PVAc provide hydroxyl groups effectively via hydrolysis reactions with either acid or base catalysts, particularly in alcohol solvents by ester exchange ( Scheme 1, bottom). Therefore, it was expected that PVAc would produce homogeneous PVA polymer hybrids by hydrolysis of the functional groups, if sufficient acid catalyst was employed. The relation between the rate of hydrolysis of PVAc and that of silica gel formation might be critical for the homogeneity of PVA polymer hybrids. To control these factors, the acid catalyst and the reaction temperature were varied.

The polymer hybrids were prepared according to Scheme 2. PVAc was added to a methanol solution of TMOS and the volume of $0.1 \mathrm{M} \mathrm{HCl} \mathrm{aq} \mathrm{was}$ altered from 0.02 to $0.60 \mathrm{ml}$. The weight ratio of organic polymer to TMOS was 0.2 . The mixture was then heated at $60{ }^{\circ} \mathrm{C}$ for seven days to yield homogeneous and transparent glassy materials, though the samples with high acid-catalyst content became dark.

The degree of hydrolysis was evaluated with FTIR. As illustrated in Fig. 1 the intensity of the 


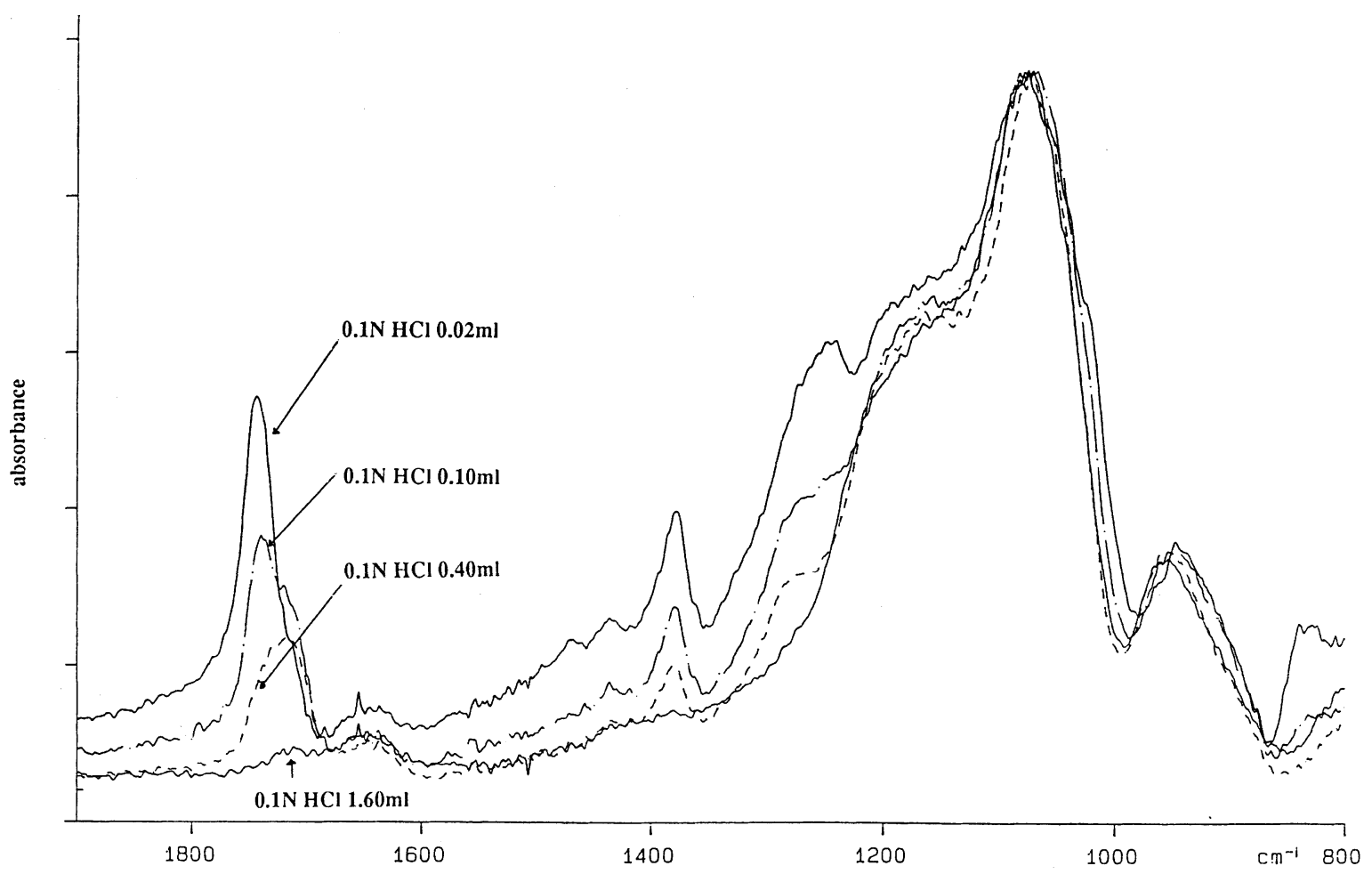

Figure 1 IR spectra for hydrolysis of poly(vinyl alcohol) hybrids.

carbonyl stretching vibration peak decreased with an increase of the amount of catalyst and it almost disappeared when the acid content was $1.6 \mathrm{ml}$. It was also observed that the peak shifted to lower wavenumbers due to the hydrogen-bonding inter- action between silanol groups in the silica gel with an increase of the acid content as reported previously. ${ }^{45}$ The degree of hydrolysis was calculated by comparing the relative intensity due to the carbonyl groups with that of the $\mathrm{Si}-\mathrm{O}-\mathrm{Si}$ stretching

Table 1 Preparation of poly(vinyl alcohol) hybrids ${ }^{\mathrm{a}}$

\begin{tabular}{lcccccc}
\hline Run & $\begin{array}{c}\text { PVAc/TMOS } \\
(\mathrm{w} / \mathrm{w})\end{array}$ & $\begin{array}{c}\text { Reaction } \\
\text { temperature }\left({ }^{\circ} \mathrm{C}\right)\end{array}$ & $\begin{array}{c}\text { Vol. of 0.1 M } \\
(\mathrm{ml})\end{array}$ & Appearance & $\begin{array}{c}\text { Weight loss } \\
(\%)^{\mathbf{b}}\end{array}$ & $\begin{array}{c}\text { Degree of } \\
\text { hydrolysis }(\%)^{\mathrm{c}}\end{array}$ \\
\hline 1 & $1: 5$ & r.t. & 0.02 & Transparent & 39.3 & 0 \\
2 & $1: 5$ & r.t. & 0.10 & Transparent & 39.3 & 5.22 \\
3 & $1: 5$ & r.t. & 0.40 & Transparent & 38.3 & 14.0 \\
4 & $1: 5$ & r.t. & 1.60 & Turbid & 21.5 & 75.2 \\
5 & $1: 5$ & 60 & 0.02 & Transparent & 46.2 & 0 \\
6 & $1: 5$ & 60 & 0.10 & Transparent & 41.1 & 28.6 \\
7 & $1: 5$ & 60 & 0.40 & Transparent & 35.0 & 47.3 \\
8 & $1: 5$ & 60 & 1.60 & Transparent & 25.9 & 85.2 \\
9 & $1: 2$ & 60 & 0.02 & Transparent & 71.7 & 0 \\
10 & $1: 2$ & 60 & 0.10 & Transparent & 53.3 & 7.12 \\
11 & $1: 2$ & 60 & 0.40 & Transparent & 51.3 & 36.0 \\
12 & $1: 2$ & 60 & 1.60 & Transparent & 45.8 & 61.4 \\
\hline
\end{tabular}

${ }^{\mathrm{a}}$ To a methanol solution $(20 \mathrm{ml})$ of PVAc $(0.4 \mathrm{~g}$ or $1.0 \mathrm{~g})$, TMOS $(2.0 \mathrm{~g})$ and $0.1 \mathrm{M} \mathrm{HCl}$ were added with stirring. The mixture was heated at $60^{\circ} \mathrm{C}$ for one week, or at room temperature for two weeks.

${ }^{\mathrm{b}}$ Calculated by TGA measurement in air.

${ }^{c}$ Calculated by FTIR. 

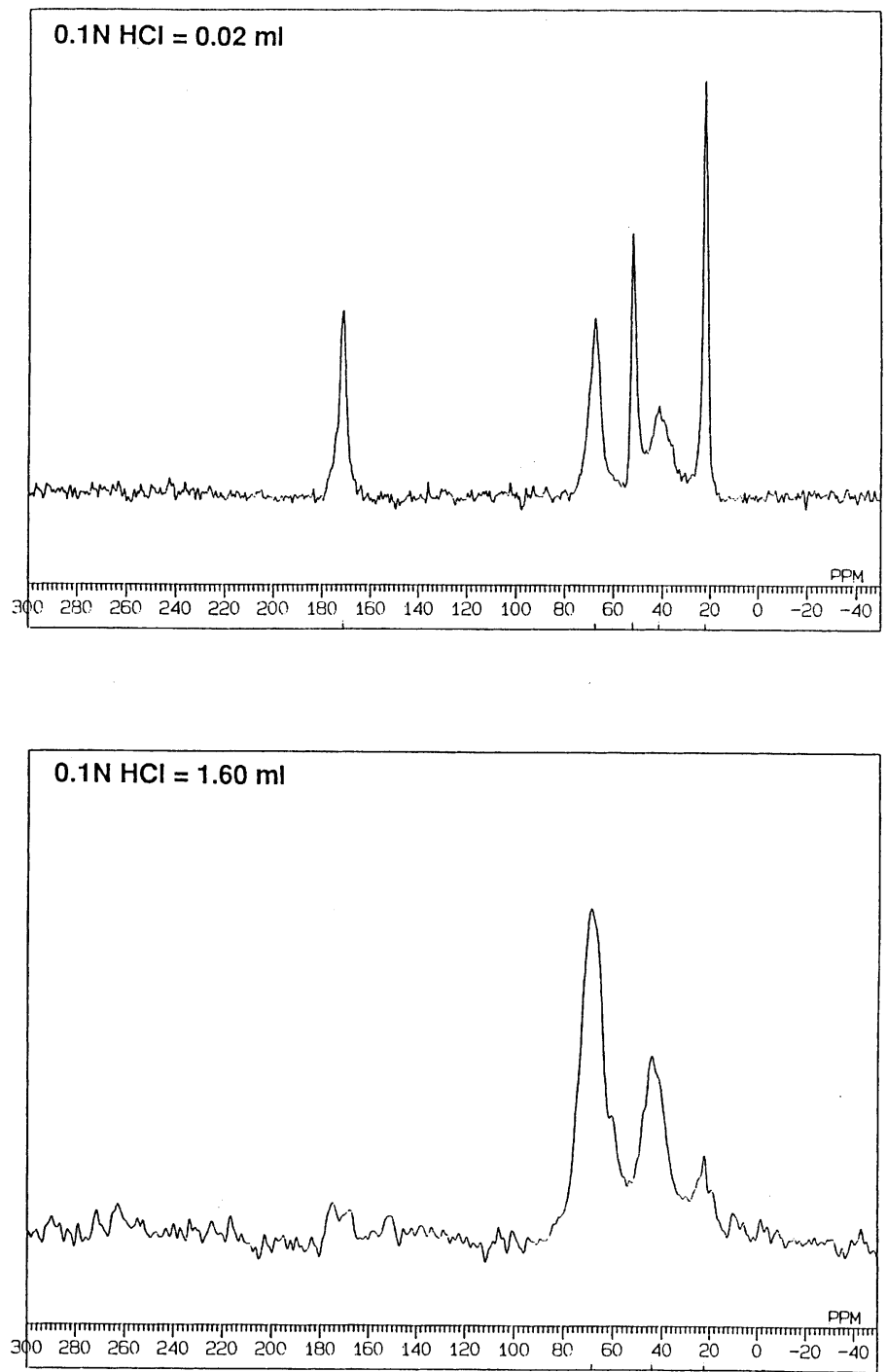

Figure $2{ }^{13} \mathrm{C}$ CP/MAS NMR spectra of poly(vinyl alcohol) hybrids.

vibration peak of each hybrid. However, as shown in Table 1 , the content of organic elements decreased when the acid content increased since the polymer would lose the acetyl groups through hydrolysis. Consequently, the decrease of the content of organic polymers would reduce the relative intensity of the carbonyl stretching vibration to that of $\mathrm{Si}-\mathrm{O}-\mathrm{Si}$, regardless of the degree of hydrolysis. To obtain the precise degree of hydrolysis, the change in organic contents was taken into account. The intensity due to the carbonyl groups was divided by the content of organic elements in

C) 1998 John Wiley \& Sons, Ltd. each hybrid and the corrected values were used to examine the degree of hydrolysis. The results are shown in Table 1 and are illustrated in Fig. 1. When the reaction was conducted at this temperature, the degree of hydrolysis increased as the amount of catalyst, while the high homogeneity was maintained in all samples: $85.2 \%$ of the carbonyl groups were found to be hydrolyzed with $1.6 \mathrm{ml}$ of the acid catalyst.

The degree of hydrolysis was also confirmed by solid-state ${ }^{13} \mathrm{C}$ CP/MAS NMR (Fig. 2). The peak for the carbonyl group was observed at $170 \mathrm{ppm}$

Appl. Organometal. Chem. 12, 755-762 (1998) 


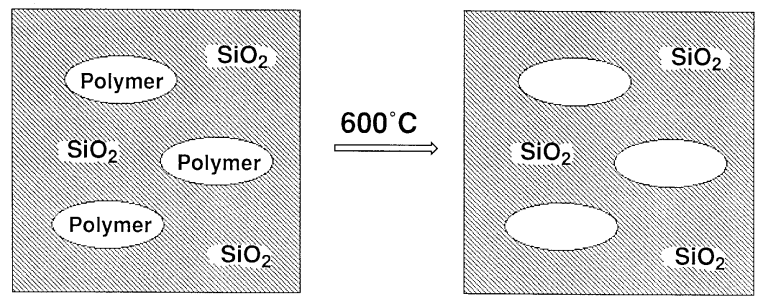

Scheme 3 Removal of organic components from polymer hybrids by sintering at $600{ }^{\circ} \mathrm{C}$ (schematic).

while the peak for methyne carbon at $67 \mathrm{ppm}$, the methylene carbon at $41 \mathrm{ppm}$ and the methyl carbon at $22 \mathrm{ppm}$ were observed in the hybrid prepared with $0.02 \mathrm{ml}$ of the catalyst. The peak at $52 \mathrm{ppm}$ corresponded to the carbon of the residual methoxy group of TMOS. In contrast, when the acid content was increased to $1.6 \mathrm{ml}$, the peak at $170 \mathrm{ppm}$ almost disappeared. The methyl carbon was also diminishing. Again the result indicates that PVAc was effectively hydrolyzed in the silica matrix to afford PVA polymer hybrid.

The same reaction was also performed at room temperature (r.t., $15^{\circ} \mathrm{C}$ ). As shown in Table 1, hydrolysis of the carbonyl groups rose as the amount of catalyst present increased at that temperature, too: $75.2 \%$ of the carbonyl groups were hydrolyzed with $1.6 \mathrm{ml}$ of the catalyst. In contrast to the reaction at $60{ }^{\circ} \mathrm{C}$, however, the homogeneity of the hybrid deteriorated significantly with $1.6 \mathrm{ml}$ of $0.1 \mathrm{M} \mathrm{HCl}$.

It has been reported that the gelation rate of alkoxysilanes is highly dependent on temperature. ${ }^{48}$ The gelation rate becomes faster with raising temperature. The declining homogeneity could therefore be attributed to the longer gelation time of TMOS at room temperature. It thus caused the hydrolysis of PVAc 'outside' the silica matrix and the aggregation of the PVA being formed, with growing of silica gel. These results indicate that kinetic control plays a more important role than the thermal stability of the hybrids. The homogeneity would be maintained once the polymer is locked inside the silica gel via the hydrogen-bonding interaction of the acetyl and the silanol groups, though PVA and silica gel hybrids are originally immiscible.

The PVA content was successfully increased to $45.8 \%$ of the total weight of the polymer hybrid. For PVAc, the initial weight ratio of 1:2 for PVAc/ TMOS was added into a reaction mixture of TMOS and the solution was heated at $60^{\circ} \mathrm{C}$ with various amounts of the catalyst (Table 1). The degree of

(C) 1998 John Wiley \& Sons, Ltd. hydrolysis increased again with the increase of the amount of catalyst and the polymer hybrid maintained its high uniformity without any phase separation.

The homogeneity of the polymer hybrids obtained was evaluated by nitrogen sorption porosimetry of a porous silica that was obtained by charring the PVA hybrid (Table 1 , run 4) at $600{ }^{\circ} \mathrm{C}$. The organic fractions would be removed from the polymer hybrids by sintering the hybrids at $600{ }^{\circ} \mathrm{C}$ without affecting their morphology (Scheme 3). ${ }^{41,49}$ The homogeneity of the original polymer hybrids could be verified consequently by measuring the pore size distribution of the porous silica obtained.

As is shown in Fig. 3 the nitrogen isotherm of the porous silica that was obtained from the homogeneous polymer hybrid (Table 1, run 4) showed a steep increase at low pressure, which indicates adsorption by micropores, and a following plateau region, meaning adsorption by the surface area. ${ }^{50} \mathrm{~A}$ surface area, a pore volume and a pore size were

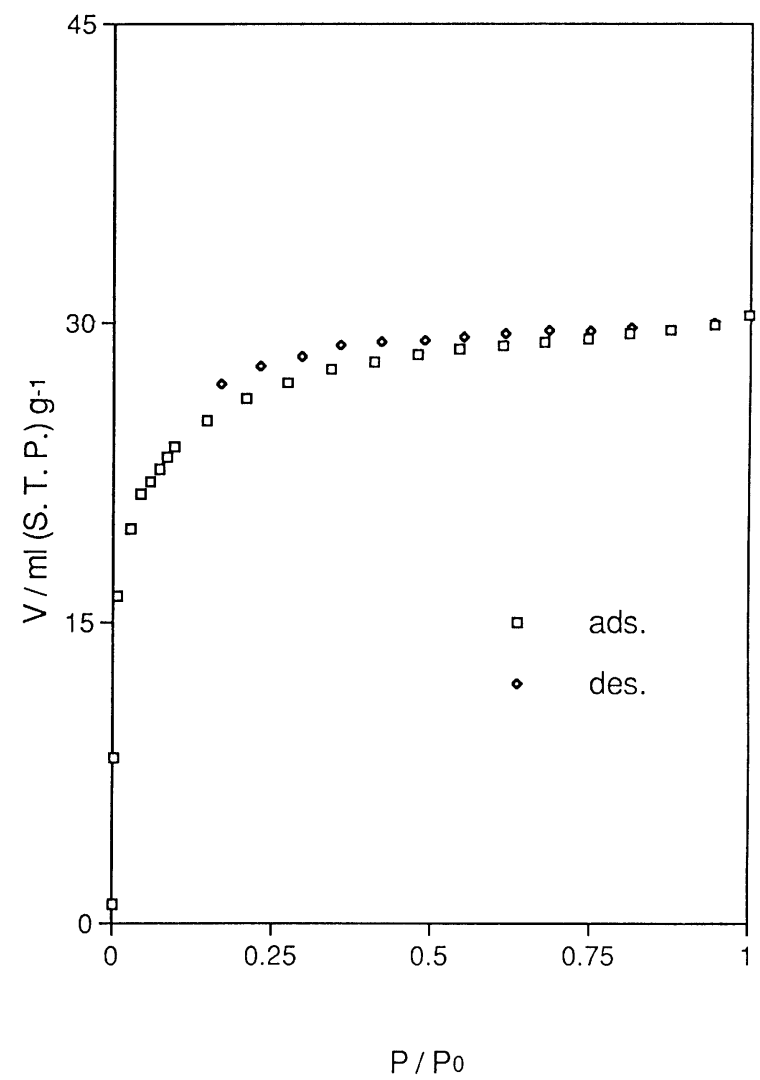

Figure 3 Isothermal curve of the porous silica.

Appl. Organometal. Chem. 12, 755-762 (1998) 


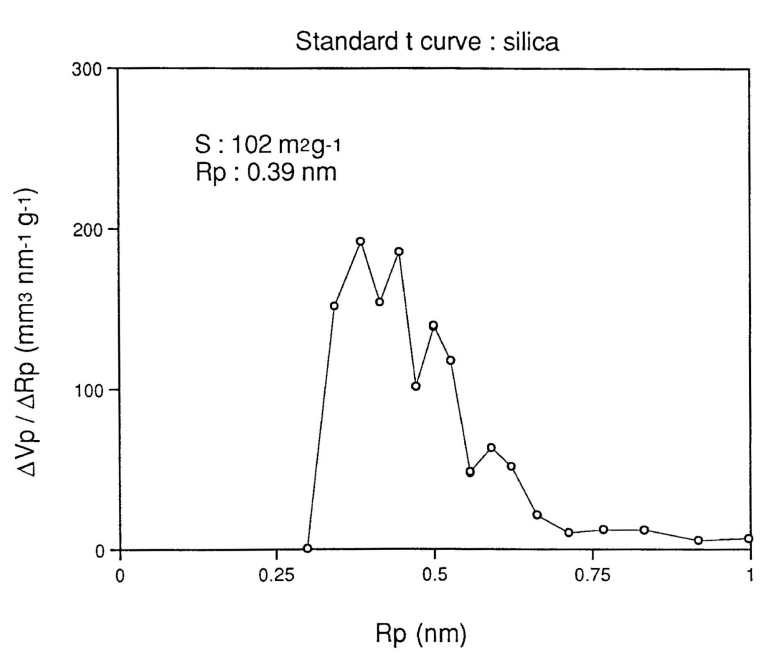

Figure 4 Pore size distribution of the porous silica (S; surface area, $\mathrm{Vp}$; pore volume, $\mathrm{Rp}$; pore size).

determined by the MP method. ${ }^{44}$ As shown in Fig. 4 the pore size distribution has a peak around $0.39 \mathrm{~nm}$ and the calculated surface area yielded the value of $102 \mathrm{~m}^{2} \mathrm{~g}^{-1}$. All these results suggest the dispersion of PVA at the ångstrom level.

\section{CONCLUSION}

It was confirmed that the in-situ hydrolysis of PVAc in the sol-gel reaction mixture with TMOS could be an effective technique for the preparation of homogeneous PVA and silica gel polymer hybrids. The dependence of the homogeneity on temperature indicated a critical role of the physical entrapment of the polymer by the silica matrix for the uniform dispersion of the polymer.

Acknowledgment The authors thank Dr T. Yazawa and Mr. K Kuraoka of Osaka National Research Institute for their help in the pore size measurements. This work was partly supported by a Grant-in-Aid for Scientific Research on Priority Areas (No. 08231242), Ministry of Education, Science, Sports and Culture, Japan.

\section{REFERENCES}

1. C. J. Wung, Y. Pang, P. N. Prasad and F. E. Karasz, Polymer 32, 605 (1991).

2. S. Motakef, T. Suratwala, R. L. Roncone, J. M. Boulton, G. Teowee, G. F. Neilson and D. R. Uhlmann, J. Non-Cryst. Solids 178, 31 (1994).

(C) 1998 John Wiley \& Sons, Ltd.
3. S. Motakef, T. Suratwala, R. L. Roncone, J. M. Boulton, G. Teowee and D. R. Uhlmann, J. Non-Cryst. Solids 178, 37 (1994).

4. M. Yoshida and P. N. Prasad, Appl. Optics 35, 1500 (1996).

5. C. Xu, L. Eldada, C. Wu, R. A. Norwood, L. W. Shacklette, J. T. Yardley and Y. Wei, Chem. Mater. 8, 2701 (1996).

6. B. C. Dave, B. Dunn, J. S. Valentine and J. I. Zink, Anal. Chem. 66, 1120 (1996).

7. C. Claude, B. Garetz, Y. Okamoto and S. Tripathy, Mater. Lett. 14, 336 (1992).

8. B. L. Davies, M. Samoc and M. Woodruff, Chem. Mater. 8, 2586 (1996).

9. G.-H. Hsiue, R.-H. Lee and R.-J. Jeng, Chem. Mater. 9, 883 (1997).

10. B. Lebeau, S. Brasselet, J. Zyss and C. Sanchez, Chem. Mater. 9, 1012 (1997).

11. G. S. Sur and J. E. Mark, Eur. Polym. J. 21, 1051 (1985).

12. J. E. Mark and G. S. Sur, Polym. Bull. 14, 325 (1985).

13. S. J. Clarson and J. E. Mark, Polym. Commun. 28, 249 (1987).

14. C.-C. Sun and J. E. Mark, Polymer 30, 104 (1989).

15. J. E. Mark, Chemtech April, 230 (1989).

16. H.-H. Huang, B. Orler and G. L. Wilkes, Macromolecules 20, 1322 (1987).

17. M. T. Reetz, A. Zonta and J. Simpelkamp, Angew. Chem., Int. Ed. Engl. 34, 301 (1995).

18. M. A. Harmer, W. E. Farneth and Q. Sun, J. Am. Chem. Soc. 118, 7708 (1996).

19. U. Schubert, New J. Chem. 18, 1049 (1994).

20. S. P. Nunes, J. Schultz and K.-V. Peinemann, J. Mater. Sci. Lett. 15, 1139 (1996).

21. M. Smaihi, T. Jermoumi, J. Marignan and R. D. Noble, $J$. Membr. Sci. 116(2), 211 (1996).

22. R. Tamaki, K. Naka, Y. Chujo, K. Kuraoka and T. Yazawa, Polym. Prepr. Jpn. 46, E499 (1997).

23. J. Marchese, N. Ochoa and C. Pagliero, J. Chem. Tech. Biotechnol 63, 329 (1995).

24. C. Guizard and P. Lacan, New J. Chem. 18, 1097 (1994).

25. H. Schmidt, H. Scholze and A. Kaiser, J. Non-Cryst. Solids 63, 1 (1984).

26. C. J. Brinker, K. D. Keefer, D. W. Schaefer, R. A. Assink, B. D. Kay and C. S. Ashley, J. Non-Cryst. Solids 63, 45 (1984).

27. F. Orgaz and H. Rawson, J. Non-Cryst. Solids 82, 57 (1986).

28. L. W. Kelts, N. J. Ejjinger and S. M. Melpolder, J. NonCryst. Solids 83, 353 (1986).

29. C. J. Brinker and G. W. Scherer, J. Non-Cryst. Solids 70, 301 (1985).

30. C. J. Brinker and G. W. Scherer, Sol-Gel Science, Harcourt Brace, Boston, 1990.

31. Y. Chujo, E. Ihara, S. Kure and T. Saegusa, Macromolecules 26, 5681 (1993).

32. M. Toki, T. Y. Chow, T. Ohnaka, H. Samura and T Saegusa, Polym. Bull. 29, 653 (1992).

33. T. Saegusa and Y. Chujo, J. Macromol. Sci. - Chem. A27, 1603 (1990).

34. Y. Chujo and T. Saegusa, Adv. Polym. Sci. 100, 11 (1992).

35. Y. Chujo, J. Thermoplastics Japan 16, 99 (1995).

Appl. Organometal. Chem. 12, 755-762 (1998) 
36. Y. Chujo, E. Ihara, S. Kure, N. Suzuki and T. Saegusa, Makromol. Chem., Macromol. Symp. 42/43, 303 (1991).

37. Y. Chujo, Organic/Inorganic Polymer Hybrids, Vol. 6 p. 4793 CRC Press, Boca Raton, (1996).

38. Y. Chujo, Polym. Mater. Sci. Eng. 74, 65 (1996).

39. T. Saegusa and Y. Chujo, Makromol. Chem. Macromol. Symp. 51, 1 (1991).

40. T. Saegusa and Y. Chujo, Makromol. Chem., Macromol. Symp. 64, 1 (1992).

41. Y. Chujo, H. Matsuki, S. Kure, T. Saegusa and T. Yazawa, J. Chem. Soc., Chem. Commun. 635 (1994).

42. R. Tamaki, T. Fujita and Y. Chujo, 4th Pac. Polym. Conf. Prepr. 211 (1995).

43. T. D. Rathke and S. M. Hudson, J. Macromol. Sci. - Rev. Macroml. Chem. Phys. C34(3), 375 (1994).
44. R. S. Mikhail, S. Brunauer and E. E. Bodor, J. Colloid. Interf. Sci. 269, 45 (1968).

45. C. J. T. Landry and B. B. K. Coltrain, J. Macromol. Sci. Pure Appl. Chem. A31(12), (1965).

46. J. J. Fitzgerald, C. J. T. Landry and J. M. Pochan, Macromolecules 25, 3715 (1992).

47. C. J. T. Landry, B. K. Coltrain, M. R. Landry, J. J. Fitzgerald and V. K. Long, Macromolecules 26, 3702 (1993).

48. M. W. Colby, A. Osaka and J. D. Mackenzie, J. Non-Cryst. Solids 82, 37 (1986).

49. D. A. Loy and K. J. Shea, Chem. Rev. 95, 1431 (1995).

50. S. Kondo, T. Ishikawa and I. Abe, Science of Adsorption (Kyutyaku no Kagaku), 1st edn, Maruzen, Tokyo, (1991). 